\title{
Erratum to: A Critical Update on Psychological Interventions for Bipolar Disorders
}

\author{
Eduard Vieta • Isabella Pacchiarotti • Marc Valentí • \\ Lesley Berk • Jan Scott • Francesc Colom
}

Published online: 4 February 2010

(C) Springer Science+Business Media, LLC 2010

\section{Erratum to: Curr Psychiatry Rep}

DOI 10.1007/s11920-009-0075-0

The abovementioned article was published in the December 2009 issue of Current Psychiatry Reports (volume 11, issue 6). The article inadvertently listed the first name of the fourth author incorrectly. The name should have been listed as Lesley Berk.

The online version of the original article can be found at http://dx.doi. org/10.1007/s11920-009-0075-0.

E. Vieta $(\varangle) \cdot$ I. Pacchiarotti $\cdot$ M. Valentí $\cdot$ F. Colom Bipolar Disorders Program, Hospital Clinic of Barcelona, IDIBAPS, CIBERSAM,

Villarroel 170,

Barcelona 08036, Spain

e-mail: evieta@clinic.ub.es

L. Berk

University of Melbourne, Barwon Health and The Geelong Clinic,

Orygen Research Centre,

Parkville Victoria, Australia

J. Scott

Royal Victoria Infirmary, University of Newcastle upon Tyne and Institute of Psychiatry, London, UK 